\title{
Well Screen and Optimal Time of Refracturing: A Barnett Shale Well
}

\author{
Shayan Tavassoli, ${ }^{1}$ Wei Yu, ${ }^{1}$ Farzam Javadpour, ${ }^{2}$ and Kamy Sepehrnoori ${ }^{1}$ \\ ${ }^{1}$ Department of Petroleum and Geosystems Engineering, The University of Texas at Austin, Austin, TX 78712, USA \\ ${ }^{2}$ Bureau of Economic Geology, Jackson School of Geosciences, The University of Texas at Austin, Austin, TX 78713, USA
}

Correspondence should be addressed to Farzam Javadpour; farzam.javadpour@beg.utexas.edu

Received 30 January 2013; Accepted 1 April 2013

Academic Editor: Jorge Ancheyta

Copyright ( 2013 Shayan Tavassoli et al. This is an open access article distributed under the Creative Commons Attribution License, which permits unrestricted use, distribution, and reproduction in any medium, provided the original work is properly cited.

\begin{abstract}
Gas-production decline in hydraulically fractured wells in shale formations necessitates refracturing. However, the vast number of wells in a field makes selection of the right well challenging. Additionally, the success of a refracturing job depends on the time to refracture a shale-gas well during its production life. In this paper we present a numerical simulation approach to development of a methodology for screening a well and to determine the optimal time of refracturing. We implemented our methodology for a well in the Barnett Shale, where we had access to data. The success of a refracturing job depends on reservoir characteristics and the initial induced fracture network. Systematic sensitivity analyses were performed so that the characteristics of a shale-gas horizontal well could be specified as to the possibility of its candidacy for a successful refracturing job. Different refracturing scenarios must be studied in detail so that the optimal design might be determined. Given the studied trends and implications for a production indicator, the optimal time for refracturing can then be suggested for the studied well. Numerical-simulation results indicate significant improvement (on the order of 30\%) in estimated ultimate recovery (EUR) after refracturing, given presented screen criteria and optimal-time selection.
\end{abstract}

\section{Introduction}

Shale-gas resources, predominantly lithified clays with low permeability [1], are considered unconventional gas reservoirs and important resources for the United States. However, gas production from these low-permeability resources is much greater than what is anticipated owing to non-Darcy flows and different sources of gas in their formations [2]. Gas flow is sourced from stored gas in nanopore networks and adsorbed gas on organic materials in the shale formations. However, new techniques are required for access to and economical production from these resources.

Recent advances in hydraulic-fracturing techniques have resulted in economic production from shale-gas reservoirs. Effective fracturing techniques make for successful economic production from extremely low (on the order of nanodarcies) permeability formations because they create a large, stimulated reservoir volume $[3,4]$. Such a success would be attributed to the potential for developing complex fracture networks, which could significantly improve reservoirwellbore connectivity. Refracturing is a process of improving production rates and ultimate recovery, which is an economical alternative to infill drilling. Although refracturing seems an excellent method of significantly increasing gas production, only $15 \%$ to $20 \%$ of refractured wells achieve any desired improvement in practice [5-7]. Therefore, a reliable and systematic approach is critical to an increase in the success of refracturing jobs. Several published works [8-11] have suggested a selection of methodologies for finding good shale-gas-well candidates for refracturing. However, application of these methods is limited, and results are unsatisfactory in horizontal-well or complex-fracture-network cases or when adequate completion and reservoir/geology data sets are lacking. With the aid of numerical-simulation methods, 
however, we are now able to study well performance properly by considering the presence of a complex fracture network, a tight matrix, and initial hydraulic fractures.

Field results demonstrate that refracturing success can be attributed to different parameters, such as the existing fracture network and reservoir properties, and a successful refracturing job should increase reservoir-wellbore connectivity, which is associated with further opening, extension, and reorientation of existing fractures. Reorientation is generally perpendicular to an initial hydraulic fracture as the result of minimum and maximum stress reversal, which occurs if induced stress changes are large enough to overcome the effect of initial horizontal stress [12]. Such a reversal could be the result of the stress created by the opening of an adjacent fracture or pore-pressure alteration due to previous production periods [13-15]. In such cases, the fracture network propagates, and, as a result, a larger portion of the reservoir is stimulated, subsequently increasing gas production and ultimate recovery.

Owing to the complexity of fracture growth in many shale-gas reservoirs, accurate prediction of fracture propagation is impossible; therefore, conductivity of the fracture network and the effectiveness of stimulation treatment are difficult to predict $[16,17]$. Detailed numerical reservoir modeling is thus needed for us to better understand the mechanisms that control production in shale-gas reservoirs and to improve completion strategies and stimulation designs. First, we needed to validate our simulation model by modeling initial fractures and the refracturing process in a horizontal well in the Barnett Shale formation. Second, on the basis of our simulation model, we performed a sensitivity study on the effect of different parameters on refracturing performance. Sensitivity analyses provide insights into the dependency of the refracturing-process performance on corresponding parameters. The result would be helpful for selecting candidates for successful refracturing. We also compared results of the refracturing performance with closely spaced initial fracturing as an alternative to increasing gas recovery from the early stages of production. Note that specifying the optimal time of refracturing is crucial to maximizing performance of the process. Simulation results of refracturing at different stages of production suggest calculation of the optimal time on the basis of gas flow rate or cumulative gasproduction recovery.

\section{Methodology}

Numerical simulation is a promising method in any design or well-performance evaluation and is commonly used to predict gas production. Specifically this approach has increased in importance for shale-gas reservoirs owing to the complexity of fracture networks and the low permeability of the formations because numerical simulations are capable of modeling fracture networks. Note that fracture-network complexity and conductivity control well productivity in shale-gas reservoirs-the more complex the fracture networks (i.e., the smaller the blocks or the denser the fracture spacing), the higher the production rates $[18,19]$. Fracture networks should therefore be considered in the simulation of the refracturing process, even though their initial network fracture conductivity may be relatively low (e.g., in the Barnett Shale, it ranges from 0.5 to $5 \mathrm{md}-\mathrm{ft}$ ) $[18,20]$.

Development of numerical simulation approaches that can properly model fluid flow in tight formations and that are capable of capturing complex fracture networks and initial hydraulic fractures is important in an evaluation of well performance and an explanation of properties that affect gas recovery. Gas flow from ultralow-permeability rock through complex fracture networks must be modeled so that stimulation designs and completion strategies can be properly evaluated. Therefore, the complex fracture network and initial hydraulic fractures must be discretely characterized in these reservoir-simulation models.

We validated our simulation methodology using field data from a refractured horizontal well in the Barnett Shale formation. We selected the Barnett Shale because of the availability of production data and because, so that economically viable production rates might be attained, hydraulic-fracture stimulation is a necessity in this formation.

The simulation model is based on a dual permeability model for two-phase (gas-water) fluid flow. Such a model considers the communication between the intergranular void spaces in contrast to the dual porosity model, which neglects this communication. The dual permeability model considers flow in the two domains of matrix and fracture, whereas the dual porosity approach assumes two domains with different hydraulic and transport properties [21]. The dual permeability model allows for simulations involving gas and water transfer between the fracture and matrix domains. Gas flow velocities in matrix and fracture are calculated on the basis of (1) and (2), respectively,

$$
\begin{aligned}
& v_{g}^{m}=-\left(\frac{K_{g}^{m}}{\mu_{g}} \nabla p_{g}+\frac{D_{g}^{m}}{C_{g}^{m}} \nabla C_{g}^{m}\right), \\
& v_{g}^{f}=-\left(\frac{K_{g}^{f}}{\mu_{g}} \nabla p_{g}+\frac{D_{g}^{f}}{C_{g}^{f}} \nabla C_{g}^{f}\right),
\end{aligned}
$$

where $v_{g}$ is gas velocity, $K_{g}$ is gas permeability, $D_{g}$ is gas diffusivity, $P_{g}$ is gas pressure, $C_{g}$ is gas concentration, and $\mu_{g}$ is gas viscosity. Superscripts $m$ and $f$ represent matrix and fracture, respectively. Water-flow velocities in matrix and fracture are calculated on the basis of (3) and (4), respectively,

$$
\begin{gathered}
v_{w}^{m}=-\frac{K_{w}^{m}}{\mu_{w}} \nabla p_{w}^{m}, \\
v_{w}^{f}=-\frac{K_{w}^{f}}{\mu_{w}} \nabla p_{w}^{f},
\end{gathered}
$$


where $v_{w}$ is water velocity, $K_{w}$ is water permeability, $P_{w}$ is water pressure, and $\mu_{w}$ is water viscosity. The equations are thus simplified to represent gas flux in matrix:

$$
\begin{aligned}
\frac{\partial}{\partial t}\left(\frac{C_{g}^{m} P_{g}^{m}}{Z}\right)= & \nabla\left(\frac{P_{g}^{m}}{Z} \frac{K_{g}^{m}}{\mu_{g}} \nabla P_{g}^{m}+D_{g}^{m} \nabla \frac{P_{g}^{m}}{Z}+\frac{D_{g}^{m}}{C_{g}^{m}} \frac{P_{g}^{m}}{Z} \nabla C_{g}^{m}\right) \\
& -\frac{R T}{M}\left(q_{g}^{m f}+q_{g}^{m}\right),
\end{aligned}
$$

where $Z$ is the gas compressibility factor, $R$ is the gas constant, $T$ is temperature, $M$ is gas molecular weight, and $q_{g}$ is gas mass-flow rate per unit matrix-block volume. Superscript $m f$ represents the exchange between matrix and fracture. We can also write this equation for the aqueous phase in matrix as

$$
\frac{\partial}{\partial t}\left(\frac{\phi_{m} s_{w}^{m}}{B_{w}}\right)=\nabla\left(\frac{K_{w}^{m}}{B_{w} \mu_{w}} \nabla P_{w}^{m}\right)-\frac{R T}{M}\left(q_{w}^{m f}+q_{w}^{m}\right),
$$

where $\phi_{m}$ is matrix porosity, $s_{w}$ is water saturation, and $B_{w}$ is the water compressibility factor. As a result of simplification of the equations, gas flux in fracture becomes

$$
\begin{aligned}
\frac{\partial}{\partial t}\left(\frac{C_{g}^{f} P_{g}^{f}}{Z}\right)= & \nabla\left(\frac{P_{g}^{f}}{Z} \frac{K_{g}^{f}}{\mu_{g}} \nabla P_{g}^{f}+D_{g}^{f} \nabla \frac{P_{g}^{f}}{Z}+\frac{D_{g}^{f}}{C_{g}^{f}} \frac{P_{g}^{f}}{Z} \nabla C_{g}^{f}\right) \\
& +\frac{R T}{M}\left(q_{g}^{m f}-q_{g}^{f}\right),
\end{aligned}
$$

and also for water in fracture:

$$
\frac{\partial}{\partial t}\left(\frac{\phi_{f} s_{w}^{f}}{B_{w}}\right)=\nabla\left(\frac{K_{w}^{f}}{B_{w} \mu_{w}} \nabla P_{w}^{f}\right)+\frac{R T}{M}\left(q_{w}^{m f}-q_{w}^{f}\right)
$$

with auxiliary equations

$$
\begin{aligned}
& C_{g}^{m}=\phi_{m} s_{g}^{m}, \\
& C_{g}^{f}=\phi_{f} s_{g}^{f}, \\
& s_{g}^{m}+s_{w}^{m}=1, \\
& s_{g}^{f}+s_{w}^{f}=1 .
\end{aligned}
$$

\section{History Matching}

The simulation results presented in this work are obtained mainly by using the Computer Modeling Group (CMG) model [22]. Our modifications and methodology of using this model are presented in Section 2. In order to validate our simulation model, we modeled initial fractures and the refracturing process in a horizontal well in the Barnett Shale formation. The Barnett Shale is a Mississippian-age marine shelf deposit having a formation thickness that varies from 200 to $800 \mathrm{ft}$ through the reservoir and ultralow permeability in the range of 70-500 nanodarcies [23]. The selected well is a cased, uncemented well in the formation.

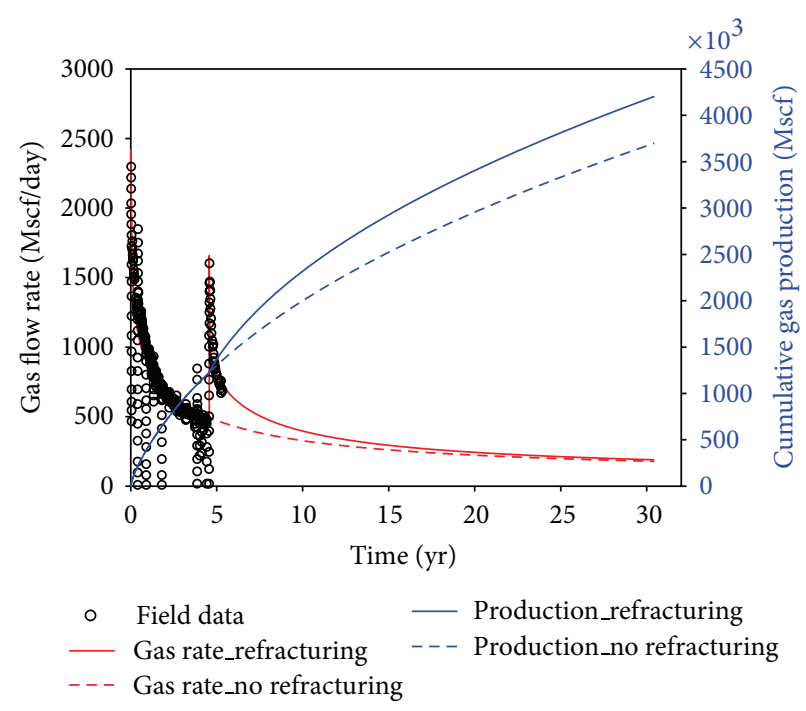

FIGURE 1: Comparison between simulation results and field data.

The well is located in the lower Barnett Shale and drilled northwest to maximize fracture-network formation. It has five equally spaced initial fractures covering a depth interval from 7,900 to $10,106 \mathrm{ft}$ [23]. The well was refractured after more than 4 years in four stages in the middle of the initial fractures. Gas production from the well was monitored and plotted for its 6 years of production (4.5 years before and 1.5 years after refracturing) (Figure 1).

Input data used in the simulation model to predict gas production from the well appear in Table 1. Refracturing after 4 years of production significantly increased productivity of the horizontal well (Figure 1), and comparison of the simulation-model results and field data verifies that our model is capable of modeling initial fractures and refracturing.

Fractures postclosure occurs during production and depletion of any shale well, closure stress, and long-term degradation of proppants controlling the extent of fracture postclosure. Gas production may decrease owing to fractureconductivity impairments, especially during later gas production. Yu and Sepehrnoori [24] recently studied the effect of reservoir depletion on fracture conductivity in the Barnett Shale. They showed that fracture conductivity reduces to about $40 \%$ of original conductivity at a limiting bottom-hole pressure of 500 psi. However, because of the great contrast between matrix permeability and fracture permeability in shale, fracture postclosure has a negligible effect $(<2 \%)$ on gas production, even after 30 years [24]. This is especially true of formations with a high Young's modulus $\left(6 \times 10^{6}\right.$ psi to $10 \times$ $\left.10^{6} \mathrm{psi}\right)$, such as the Barnett Shale.

\section{Results and Discussion}

In this section we use our verified numerical model and the present gas production rate and cumulative gas production of the studied well. In our sensitivity analyses we present the effects of formation permeability and porosity, as well 
TABLE 1: Input data used in simulation model.

\begin{tabular}{|c|c|c|}
\hline Parameter & Value(s) & Unit: field (SI) \\
\hline Model dimensions & $5000 \times 5000 \times 300(1524 \times 1524 \times 91)$ & $\mathrm{ft}(\mathrm{m})$ \\
\hline Initial reservoir pressure & $3800\left(2.62 \times 10^{7}\right)$ & psi (pa) \\
\hline BHP & $1100\left(7.58 \times 10^{6}\right)$ & psi (pa) \\
\hline Production time & 30 & year \\
\hline Reservoir temperature & $150(66)$ & ${ }^{\circ} \mathrm{F}\left({ }^{\circ} \mathrm{C}\right)$ \\
\hline Gas viscosity & $0.0201\left(2.01 \times 10^{-5}\right)$ & cp (pa.s) \\
\hline Initial gas saturation & 0.70 & fraction \\
\hline Total compressibility & $3 \times 10^{-6}\left(4.35 \times 10^{-10}\right)$ & $\mathrm{Psi}^{-1}\left(\mathrm{pa}^{-1}\right)$ \\
\hline Matrix permeability & $5 \times 10^{-4}\left(4.93 \times 10^{-19}\right)$ & $\mathrm{md}\left(\mathrm{m}^{2}\right)$ \\
\hline Matrix porosity & 0.018 & fraction \\
\hline Fracture conductivity & $1\left(3 \times 10^{-16}\right)$ & $\mathrm{md}-\mathrm{ft}\left(\mathrm{m}^{2}-\mathrm{m}\right)$ \\
\hline Fracture half-length & Varied: $\operatorname{Min}=470(143), \operatorname{Max}=1870(570)$ & $\mathrm{ft}(\mathrm{m})$ \\
\hline Fracture spacing & $550(168)$ & $\mathrm{ft}(\mathrm{m})$ \\
\hline Refracture half-length & $970(296)$ & $\mathrm{ft}(\mathrm{m})$ \\
\hline Refracture spacing & $275(84)$ & $\mathrm{ft}(\mathrm{m})$ \\
\hline Fracture height & $300(91)$ & $\mathrm{ft}(\mathrm{m})$ \\
\hline Horizontal well length & $2800(853)$ & $\mathrm{ft}(\mathrm{m})$ \\
\hline Number of fractures & 5 & number \\
\hline Number of refractures & 4 & number \\
\hline
\end{tabular}

as initial induced hydraulic-fracture conductivity on well performance. These analyses are followed by a discussion on well-screening criteria and time optimization of refracturing. We used base data (Table 1) to create simulation cases by varying individual parameters for sensitivity analyses. Gasproduction rate and cumulative gas production were plotted against time for all parameters to show the performance of the well. Each plot included well performance with and without refracturing to highlight refracturing effectiveness on gasproduction performance.

4.1. Effects of Permeability. We created two plots to show the effects of formation permeability on gas flow rate and cumulative gas production rate (Figures 2 and 3). In each plot we considered two scenarios-performance of the well without refracturing and a case of refracturing after 4 years. Intuitively we knew that both gas flow rate and cumulative gas production would improve if permeability increased. The refractured wells showed better gas flow rates and $30 \%$ to $70 \%$ improvement in cumulative gas production for the highest $(0.0005 \mathrm{md})$ and lowest $(0.00005 \mathrm{md})$ permeabilities, respectively.

4.2. Effects of Porosity. We created two plots to show the effects of formation porosity on gas flow rate and cumulative gas production rate (Figures 4 and 5). In each plot we considered two scenarios-performance of the well without refracturing and a case of refracturing after 4 years. The refractured wells showed better gas flow rates and 50\% to $70 \%$ improvement in cumulative gas production for the lowest (0.04) and highest (0.08) porosities, respectively.

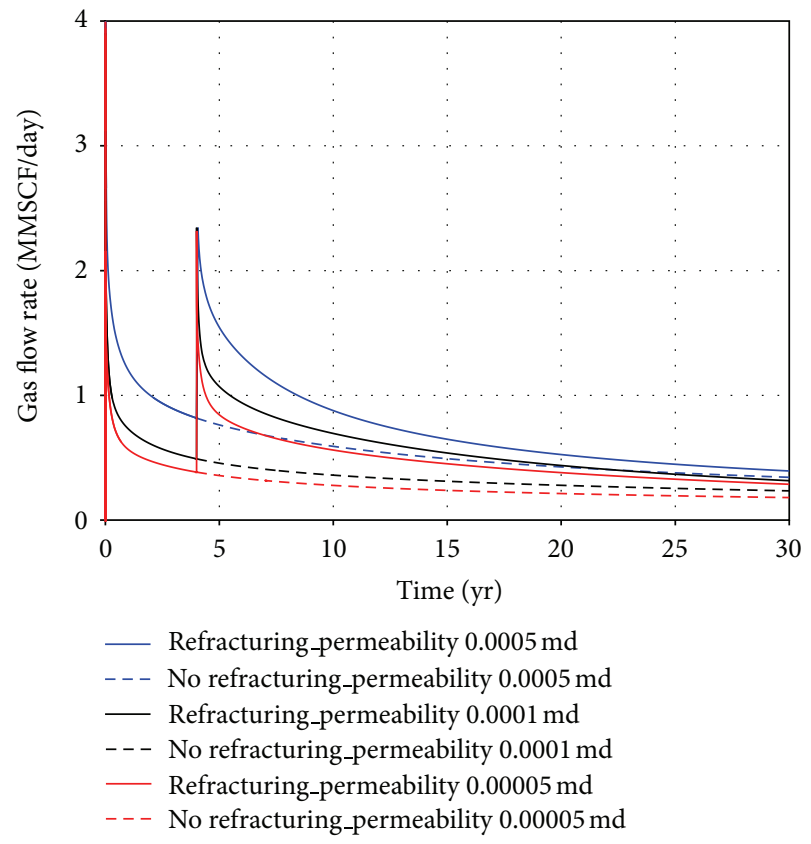

FIGURE 2: Effects of formation permeability on gas flow rate. Two scenarios: no refracturing and refracturing after 4 years of production.

4.3. Effects of Initial Fracture Conductivity. We created two plots to show the effects of initial fracture conductivity on gas flow rate and cumulative gas production rate (Figures 6 and 7). In each plot we considered two scenarios-performance of the well without refracturing and a case of refracturing after 


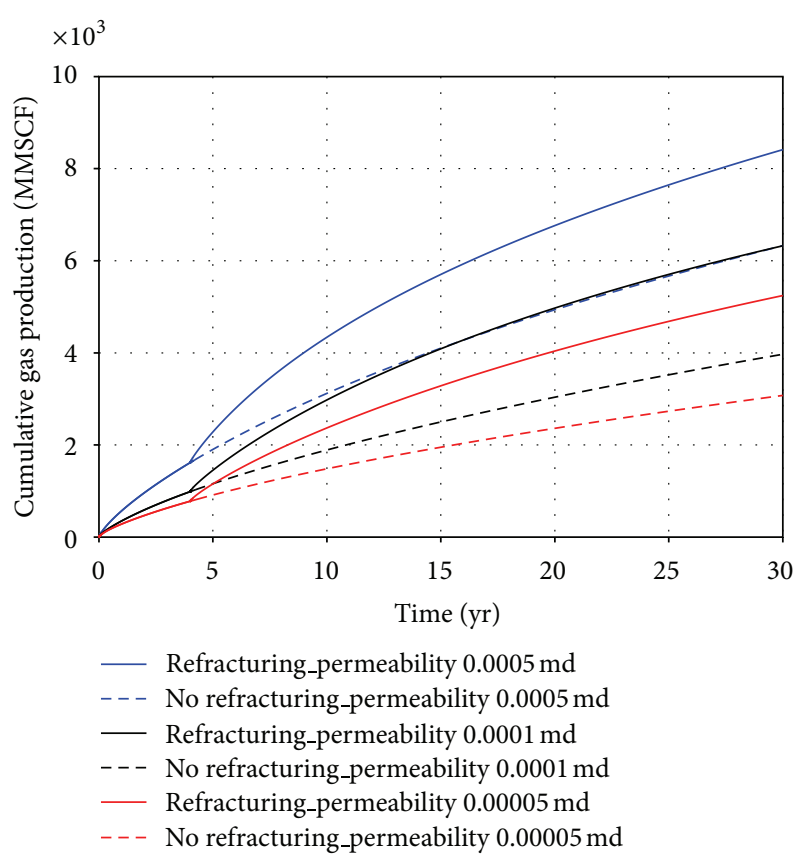

Figure 3: Effects of formation permeability on cumulative gas production. Two scenarios: no refracturing and refracturing after 4 years of production.

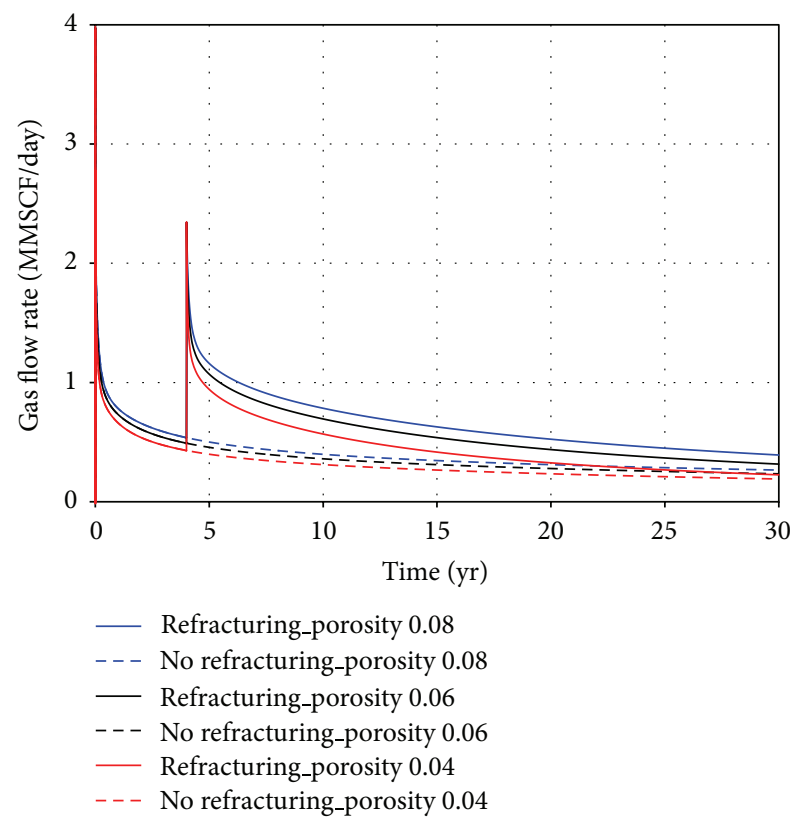

FIGURE 4: Effects of formation porosity on gas flow rate. Two scenarios: no refracturing and refracturing after 4 years of production.

4 years. Both gas-flow rate and cumulative gas production improved when initial fracture conductivity was increased. The refractured well showed better gas flow rates and 50\% to $80 \%$ improvement in cumulative gas production for the highest $(10 \mathrm{md}-\mathrm{ft})$ and the lowest $(0.1 \mathrm{md}-\mathrm{ft})$ initial fracture conductivities, respectively.

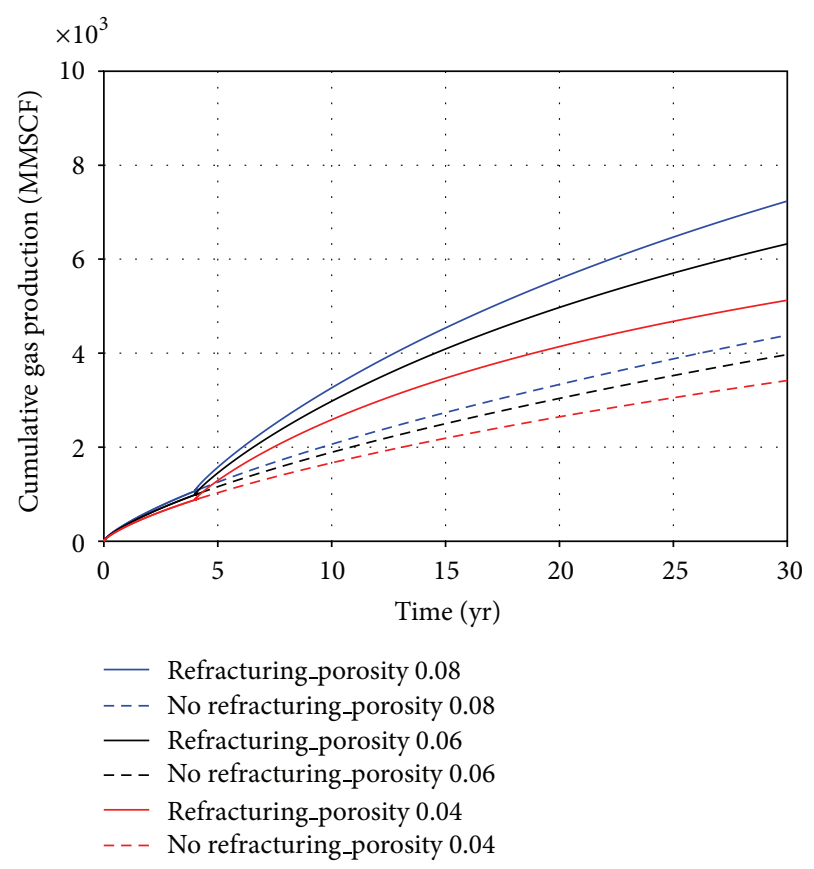

FIGURE 5: Effects of formation porosity on cumulative gas production. Two scenarios: no refracturing and refracturing after 4 years of production.

4.4. Well Screen Criteria. Cumulative gas production and gas flow rate increase as reservoir permeability, porosity, and initial fracture conductivity increase (Figures 2-7). Because increase in the trends of gas production in these cases is significant in contrast to the increase in trends of gas flow rate, we are unable to refine our selection on the basis of these trends. We therefore compared our results on the basis of production indicators to select candidate shale-gas wells for refracturing. Given the correlation between monthly incremental and 5-year cumulative gas production, wells falling off the trend line indicate wells that had good initial production but for which longer-term recovery was poor [9] (Figure 8). Because all of our cases are located on the trend line, this method adds no information about range of selection.

To determine and compare production enhancement in each case study, we introduce a production indicator, known as long-term refracturing efficiency and defined as the ratio of cumulative gas production after refracturing to its value before refracturing in 30 years of production:

Long-term refracturing efficiency

$$
=\frac{\text { Total cumulative gas production after refracturing }}{\text { Total cumulative gas production with no refracturing }} \text {. }
$$

We calculated and plotted long-term refracturing efficiency for each case and found that refracturing efficiency increases as reservoir permeability reduces to its lower limits (Figure 9). Efficiency enhancement is not that significant, 


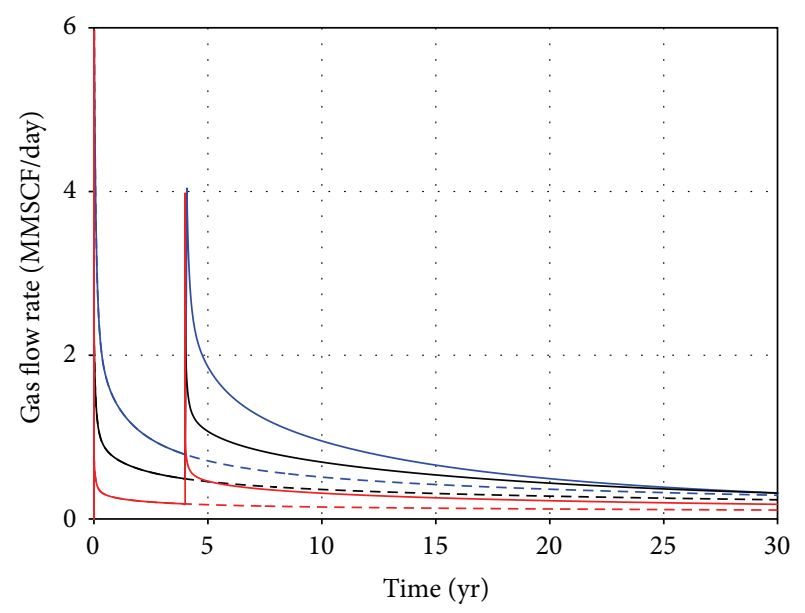

- Refracturing_fracture conductivity $10 \mathrm{md}-\mathrm{ft}$
-- No refracturing_fracture conductivity $10 \mathrm{md}-\mathrm{ft}$
- Refracturing_fracture conductivity $1 \mathrm{md}-\mathrm{ft}$
-- No refracturing_fracture conductivity $1 \mathrm{md}-\mathrm{ft}$
- Refracturing_fracture conductivity $0.1 \mathrm{md}-\mathrm{ft}$
--

FIGURE 6: Effects of initial fracture conductivity on gas flow rate. Two scenarios: no refracturing and refracturing after 4 years of production.

however, at permeability values greater than 0.0001 millidarcy. Refracturing efficiency increases as porosity increases (Figure 10). Efficiency enhancement due to refracturing is significant when porosity values are greater than $6 \%$. The difference in gas-production enhancement with respect to permeability might seem to be in contradiction to its trend with respect to porosity because of the correlation between permeability and porosity. However, note that refracturing enhances gas production from low-permeability reservoirs by forming a more complex fracture network that has been depleted from a larger stimulated reservoir volume (SRV). On the other hand, larger porosity corresponds to a larger amount of initial gas in place. Hence, refracturing enhancement cannot be responsible for an increase in gas production in cases with high-porosity values. We also studied the effect of initial fracture conductivity on the performance of refracturing. Refracturing efficiency increases as fracture conductivity decreases (Figure 11), efficiency enhancement increasing in significance for values lower than $1 \mathrm{md}-\mathrm{ft}$. Results of these simulations reveal that long-term refracturing efficiency can provide insight into the effect of each parameter and its importance. On the basis of this sensitivity study we have proposed a screening method for existing fractured horizontal wells that is based on reservoir and initial hydraulic-fracture properties (Table 2).

4.5. Initial Fracture Spacing. Here we compare results of refracturing performance with that of closely spaced initial fracturing, which can be an alternative to increasing gas recovery beginning in the early stages of production. Different values of fracture spacing $(50,100,200,350$, and $450 \mathrm{ft})$ are considered here. Refracturing in the middle of initial

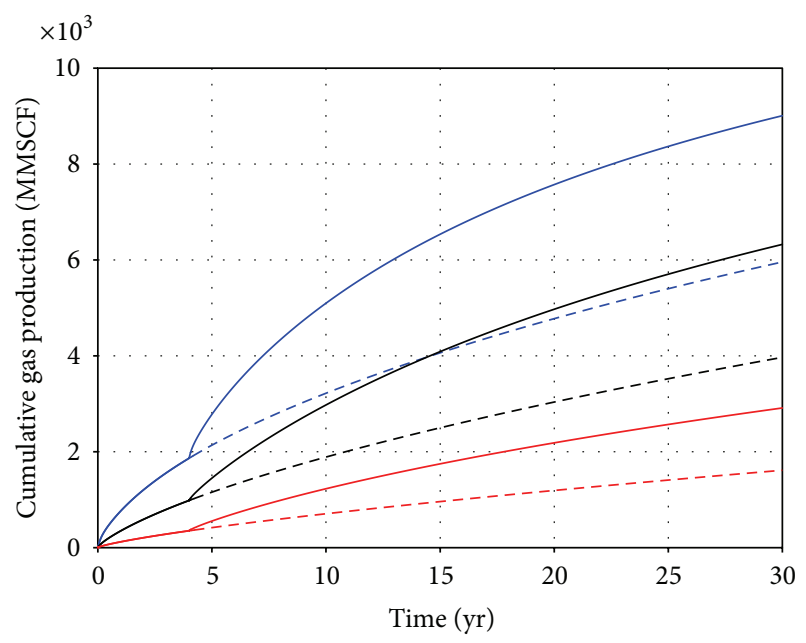

— Refracturing_fracture conductivity $10 \mathrm{md}-\mathrm{ft}$

- - - No refracturing_fracture conductivity $10 \mathrm{md}-\mathrm{ft}$

_ Refracturing_fracture conductivity $1 \mathrm{md}-\mathrm{ft}$

- - - No refracturing_fracture conductivity $1 \mathrm{md}-\mathrm{ft}$

- Refracturing_fracture conductivity $0.1 \mathrm{md}-\mathrm{ft}$

- - - No refracturing_fracture conductivity $0.1 \mathrm{md}-\mathrm{ft}$

FIGURE 7: Effects of initial fracture conductivity on cumulative gas production. Two scenarios: no refracturing and refracturing after 4 years of production.

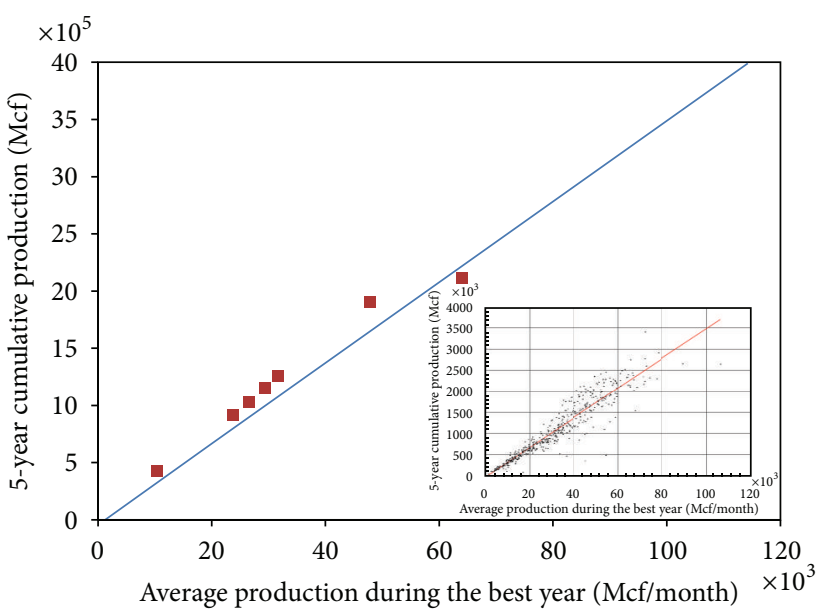

FIGURE 8: Correlation between short-term and long-term production [9], along with our simulation results.

fractures is also performed in all the cases after 4 years of production, except in cases where initial fractures are close to one another $(50 \mathrm{ft})$. The total number of fractures for each case is 57 (57 initial fractures), 57 (29 initial fractures and 28 refractures), 29 (15 initial fractures and 14 refractures), 17 (9 initial fractures and 8 refractures), and 13 (7 initial fractures and 6 refractures). Cumulative gas production from refractured wells having higher initial values of fracture spacing is similar to that of closely spaced initial fractures if the ultimate fracture spacing remains the same (Figure 12). In other words, we expect the same performance in the two cases having the same value of total fracture length, including 
TABLE 2: Well screening criteria.

\begin{tabular}{lcccc}
\hline Property & Perfect selection & Fair selection & Poor selection & Unit: field (SI) \\
\hline Permeability & $<0.0001\left(9.8 \times 10^{-20}\right)$ & $<0.0005\left(4.9 \times 10^{-19}\right)$ & $>0.0005\left(4.9 \times 10^{-19}\right)$ & $\mathrm{md}\left(\mathrm{m}^{2}\right)$ \\
Porosity & $>0.06$ & $>0.04$ & $<0.04$ & fraction \\
Fracture conductivity & $>1\left(3 \times 10^{-16}\right)$ & $<10\left(3 \times 10^{-15}\right)$ & $>10\left(3 \times 10^{-15}\right)$ & $\mathrm{md}-\mathrm{ft}\left(\mathrm{m}^{2}-\mathrm{m}\right)$ \\
\hline
\end{tabular}

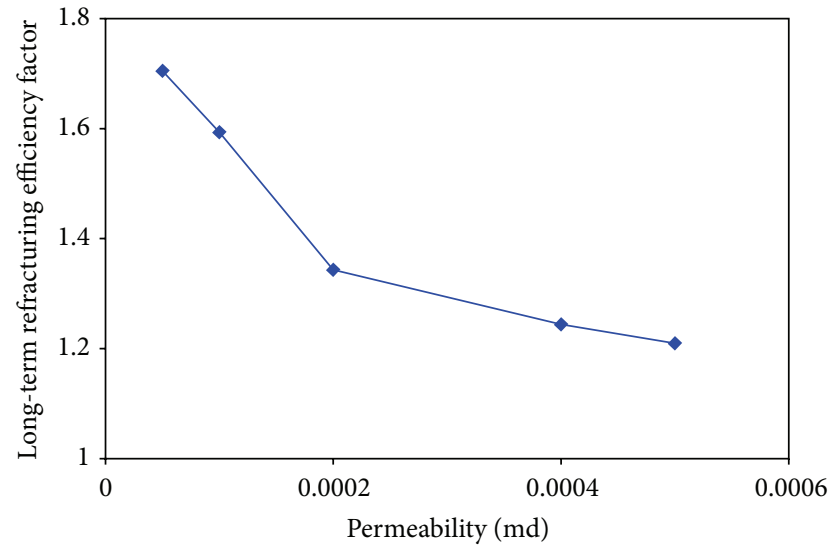

FIGURE 9: Long-term refracturing efficiency versus different permeabilities.

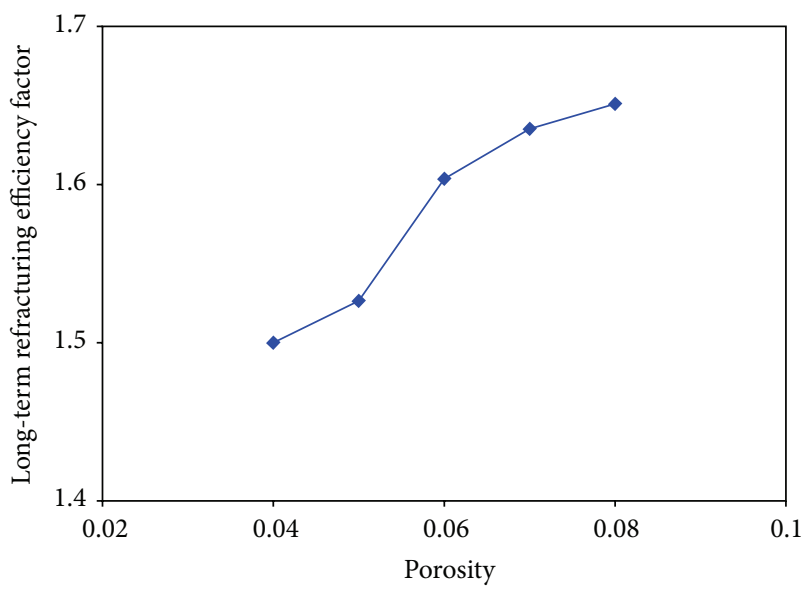

Figure 10: Long-term refracturing efficiency versus different porosities.

refractured lengths. Hence, refracturing at the proper time of production appears to be an attractive restimulation method for wells having large initial fracture spacing.

4.6. The Optimal Time to Refracture a Well. Finding the optimal time to refracture so as to maximize the performance of the refracturing job is crucial. On the basis of available field-production data of successful refracturing processes in Barnett Shale formations and the simulation results of different refracturing scenarios, we proposed an indicator for finding the proper time for refracturing.

To find the optimal time, we considered different times of refracturing. Cumulative gas production and gas flow rate

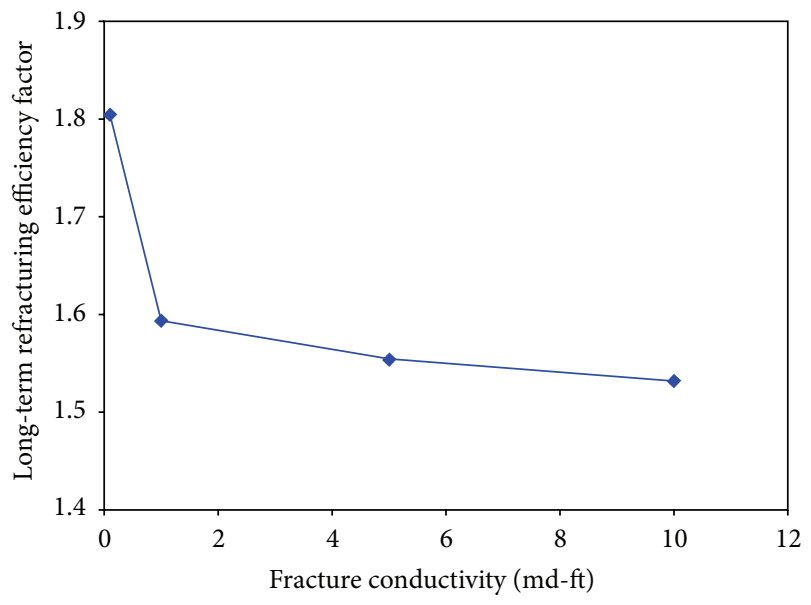

FIGURE 11: Long-term refracturing efficiency versus different fracture conductivities.

for these different cases are obtained from simulation results (Figures 13 and 14, resp.). Because of the difficulty involved in such a task, however, we studied trends in detail and proposed an indicator for comparison between various production trends.

The proposed indicator suggests that if the decline rate of gas production falls below $10 \%$ to $15 \%$, the refracturing process should be applied. The cumulative gas production result of refracturing after 2 or 3 years of production is higher than that of a well refractured after 4 years of production (Figure 13). However, the incline rate of the cumulative gas production result of refracturing after 2 or 3 years of production is still significant (more than 20\%) (Figure 15). Hence, the decline rate of gas production is pronounced early in the stimulation process, but only until it reduces below $15 \%$, at which point the initial stimulation effect has vanished and gas production levels off. Under these conditions, refracturing should be considered as a way to increase gas production from the well. Incline-decline rates can be defined as

$$
\text { Decline rate of gas production }=\frac{q_{r}^{n-1}-q_{r}^{n}}{q_{r}^{n-1}},
$$

Incline rate of cumulative gas production $=\frac{Q^{n+1}-Q^{n}}{Q^{n}}$,

where $n$ is refracturing time in years, $q_{r}$ is gas flow rate, and $Q$ is cumulative gas production. Both decline rate of gas production and incline rate of cumulative gas production during the first 6 years of a project's life reduce over that time and level off (Figure 15). According to the introduced 


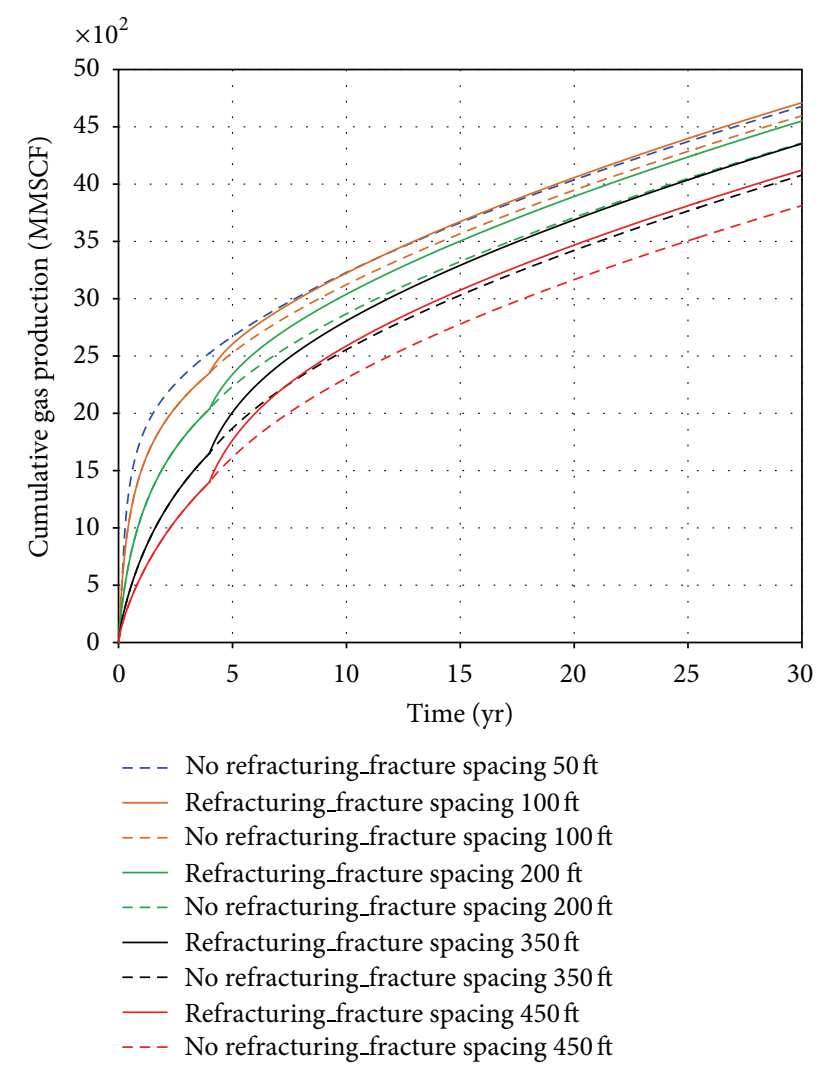

FIGURE 12: Cumulative gas production for different fracture-spacing values.

indicator, the proper time for refracturing occurs after 4 years of production because the decline rate of gas production drops to less than $15 \%$ during that fourth year.

\section{Conclusions}

We used numerical simulation to study refracturing of wells in shale formations by selecting a well in the Barnett Shale formation and simulating gas production from this well. We used the verified model to perform sensitivity studies on formation properties and initial-fracture conductivity on gas-production performance. We found that refracturing is an effective restimulation technique if it is performed for a proper candidate well and at the optimal time. Numericalsimulation results indicate significant improvements on the order of $30 \%$ in estimated ultimate recovery (EUR) after refracturing. Some specific conclusions are as follows.

(1) Our simulation model results suggest that refracturing is more effective in low-permeability reservoirs. Refracturing enhances gas production by forming a more complex fracture network and producing larger stimulated reservoir volume (SRV) in these low-permeability reservoirs. Larger porosities result in higher gas production owing to an increase in the amount of gas in place.

(2) Results show that higher values of initial fracture conductivity eliminate the need for refracturing owing

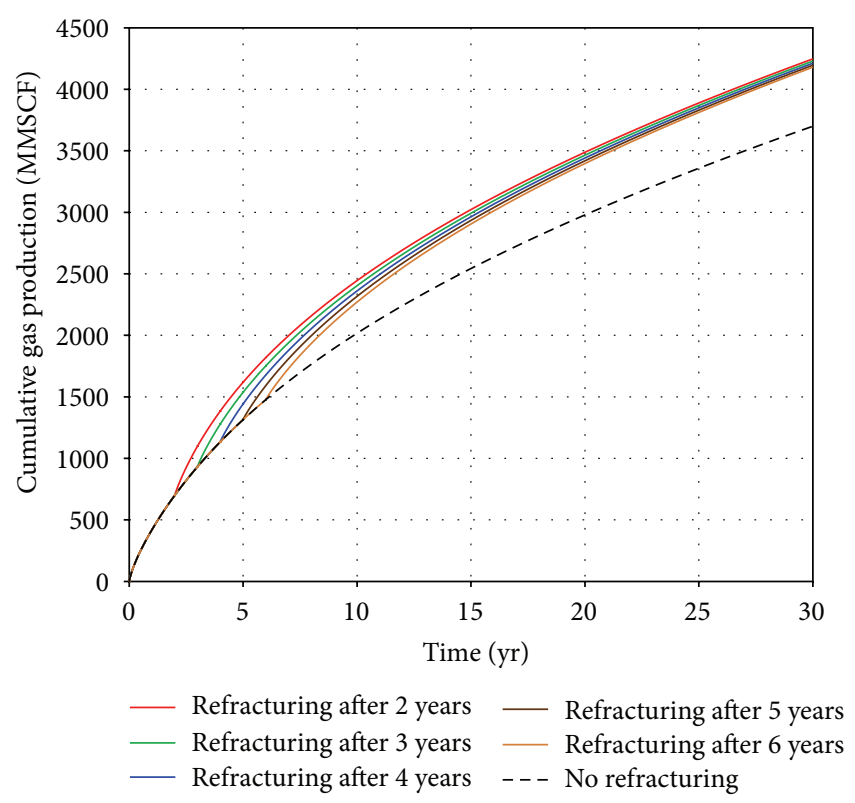

Figure 13: Cumulative gas production for different times of refracturing.

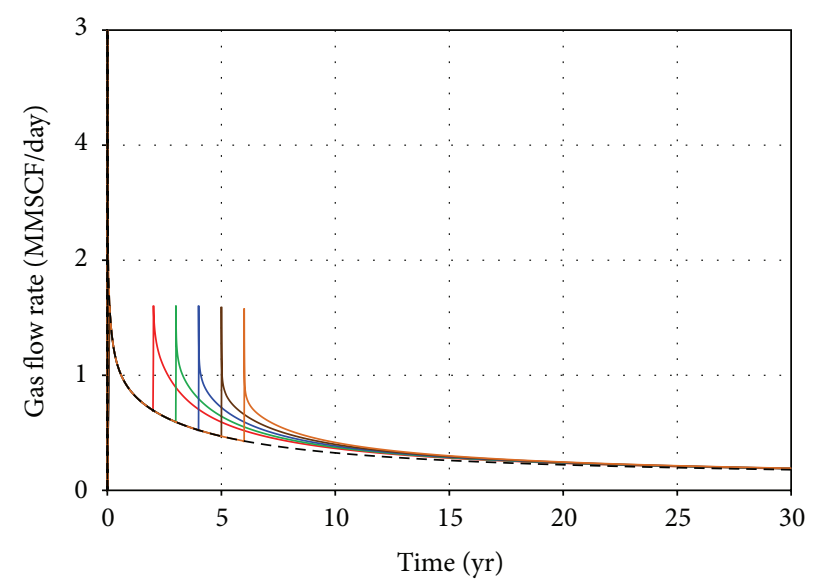

$\begin{array}{lll}- \text { Refracturing after } 2 \text { years } & - & \text { Refracturing after } 5 \text { years } \\ - \text { Refracturing after } 3 \text { years } & - & \text { Refracturing after } 6 \text { years } \\ \text { Refracturing after } 4 \text { years } & --- & \text { No refracturing }\end{array}$

FIGURE 14: Gas flow rate for different times of refracturing.

to the presence of conductive paths between wellbore and reservoir.

(3) Refracturing performance was compared with that of closely spaced initial fractures. Results show that cumulative gas production correlates with total fracture length, including refracture lengths.

(4) We developed a screening method for existing wells in a formation that was based on reservoir characteristics and initial hydraulic-fracture properties. The screening method provides perfect, fair, and poor selection categories that are based on ranges of the studied variables. 


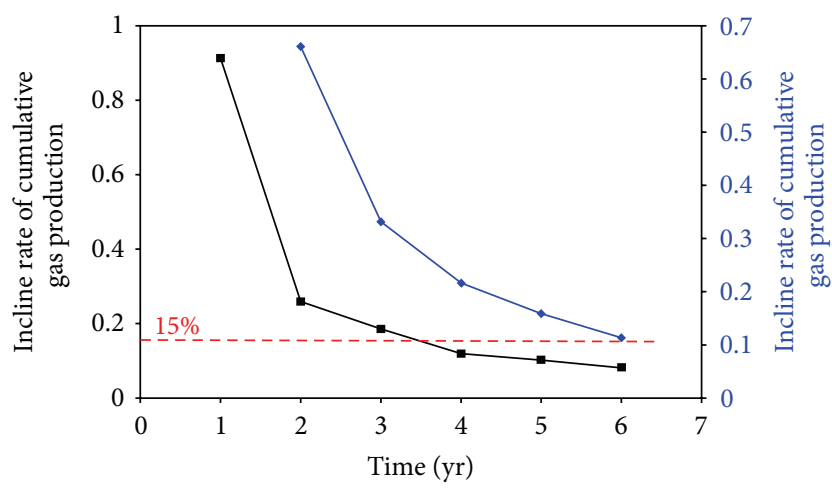

FIGURE 15: Decline rate of gas flow rate and incline rate of cumulative gas production versus time.

(5) Finding the optimal time for refracturing so as to maximize its performance is crucial. On the basis of detailed study of gas flow rate and cumulative gas production in the first 6 years of a project's life, we suggest performing refracturing at the point in the life of the project when decline of the gas flow rate falls below $10 \%$ to $15 \%$.

\section{Nomenclature}

$v: \quad$ Flow velocity, $\mathrm{m} / \mathrm{s}$

$\mu$ : Viscosity, Pa.s

p: $\quad$ Pressure, $\mathrm{Pa}$

K: $\quad$ Phase permeability, $\mathrm{m}^{2}$

C: Concentration, $\mathrm{m}^{3} / \mathrm{m}^{3}$

D: Diffusivity, $\mathrm{m}^{2} / \mathrm{s}$

$Z: \quad$ Gas-compressibility factor

$\phi: \quad$ Porosity

$B$ : $\quad$ Compressibility factor, $\mathrm{Pa}^{-1}$

R: $\quad$ Gas constant, $\mathrm{Pa} \cdot \mathrm{m}^{3} /(\mathrm{mol} \cdot \mathrm{K})$

M: $\quad$ Molar mass, $\mathrm{kg} / \mathrm{mol}$

T: $\quad$ Temperature, $\mathrm{K}$

$q$ : Mass flow rate per unit matrix-block volume, $\mathrm{kg} /\left(\mathrm{m}^{3} \cdot \mathrm{s}\right)$

$q_{r}: \quad$ Gas flow rate, MMSCF/D

Q: Cumulative gas production, MMSCF

$s: \quad$ Phase saturation.

\section{Superscripts}

$m:$ Matrix

$f:$ Fracture

$m f$ : Exchange between matrix and fracture.

\section{Subscripts}

$g:$ Gas

$w$ : Water.

\section{Acknowledgments}

The authors would like to thank Computer Modeling Group Ltd. for use of the CMG-IMEX software. They would also like to express their gratitude for financial support from the Hilcorp Energy Company and NanoGeosciences lab at the Bureau of Economic Geology (UT-Austin) and to thank Ms. L. Dieterich for editing the paper.

\section{References}

[1] F. Javadpour, D. Fisher, and M. Unsworth, "Nanoscale gas flow in shale sediments," Journal of Canadian Petroleum Technology, vol. 46, no. 10, pp. 55-561, 2007.

[2] F. Javadpour, "Nanopores and apparent permeability of gas flow in mudrocks (shales and siltstone)," Journal of Canadian Petroleum Technology, vol. 48, no. 8, pp. 16-21, 2009.

[3] N. R. Warpinski, M. J. Mayerhofer, M. C. Vincent, C. L. Cipolla, and E. R. Lolon, "Stimulating unconventional reservoirs: maximizing network growth while optimizing fracture conductivity," Journal of Canadian Petroleum Technology, vol. 48, no. 10, pp. 39-51, 2009.

[4] M. Y. Soliman and C. S. Kabir, “Testing unconventional formations," Journal of Petroleum Science and Engineering, vol. 92-93, pp. 102-1109, 2012.

[5] S. R. Reeves, "Restimulation technology for tight gas sand wells," in Proceedings of the SPE Annual Technical Conference, SPE56482, Houston, Tex, USA, 1999.

[6] D. G. Hill and S. R. Reeves, "Restimulation research to target low cost, incremental gas reserves," Gas Tips, vol. 4, no. 3, 1998.

[7] T. Lantz, "Refracture treatments proving successful in horizontal Bakken wells," SPE Production \& Operations, vol. 23, no. 3, pp. 373-378, 2008.

[8] L. P. Moore and H. Ramakrishnan, "Restimulation: candidate selection methodologies and treatment optimization," in Proceedings of the SPE Annual Technical Conference, SPE-102681, San Antonio, Tex, USA, 2006.

[9] S. Sinha and H. Ramakrishnan, "A novel screening method for selection of horizontal refracturing candidates in shale gas reservoirs," in Proceedings of the North American Unconventional Gas Conference, SPE-144032, The Woodlands, Tex, USA, 2011.

[10] N. P. Roussel and M. M. Sharma, "Selecting candidate wells for refracturing using production data," in Proocedings of the SPE Annual Technical Conference, SPE-146103, Denver, Colo, USA, 2011.

[11] A. A. Ketter, J. L. Daniels, J. R. Heinze, and G. Waters, "A field study optimizing completion strategies for fracture initiation in barnett shale horizontal wells," in Proocedings of the SPE Annual Technical Conference and Exhibition (ATCE '06), Focus on the Future, SPE-103232, pp. 4531-4536, San Antonio, Tex, USA, September 2006.

[12] E. Siebrits, J. L. Elbel, R. S. Hoover et al., "Refracture reorientation enhances gas production in Barnett Shale tight gas wells," in Proceedings of the SPE Annual Technical Conference, SPE-63030, Dallas, Tex, USA, October 2000.

[13] M. C. Vincent, "Refracs-why do they work, and why do they fail in 1000 published field studies?" in Proceedings of the SPE Annual Technical Conference, SPE-134330, Florence, Italy, 2010.

[14] M. C. Vincent, "Restimulation of unconventional reservoirs: when are refracs beneficial?" in Proceedings of the Canadian 
Unconventional Resources and International Petroleum Conference, SPE-136757, pp. 407-443, Alberta, Canada, October 2010.

[15] M. K. Fisher, J. R. Heinze, C. D. Harris, B. M. Davidson, C. A. Wright, and K. P. Dunn, "Optimizing horizontal completion techniques in the barnett shale using microseismic fracture mapping," in Proceedings of the SPE Annual Technical Conference, SPE-90051, Houston, Tex, USA, September 2004.

[16] C. L. Cipolla, E. P. Lolon, M. J. Mayerhofer, and N. R. Warpinski, "Fracture design considerations in horizontal wells drilled in unconventional gas reservoirs," in Proceedings of the SPE Hydraulic Fracturing Technology Conference, SPE-119366, pp. 366-375, The Woodlands, Tex, USA, January 2009.

[17] C. L. Cipolla, E. P. Lolon, and B. Dzubin, "Evaluating stimulation effectiveness in unconventional gas reservoirs," in Proceedings of the SPE Annual Technical Conference and Exhibition 2009, ATCE 2009, SPE-124843, pp. 3397-3417, New Orleans, La, USA, October 2009.

[18] M. J. Mayerhofer, E. P. Lolon, N. R. Warpinski et al., "What is stimulated reservoir volume?" SPE Production \& Operations, vol. 25, no. 1, pp. 89-898, 2006.

[19] C. L. Cipolla, E. P. Lolon, J. C. Erdle, and B. Rubin, "Reservoir modeling in shale-gas reservoirs," SPE Reservoir Evaluation \& Engineering, vol. 13, no. 4, pp. 638-6653, 2010.

[20] C. L. Cipolla, N. R. Warpinski, M. J. Mayerhofer, E. P. Lolon, and M. C. Vincent, "The relationship between fracture complexity, reservoir properties, and fracture treatment design," in Proceedings of the SPE Annual Technical Conference and Exhibition, SPE-115769, Denver, Colo, USA, 2008.

[21] T. Vogel, H. H. Gerke, R. Zhang, and M. T. Van Genuchten, "Modeling flow and transport in a two-dimensional dualpermeability system with spatially variable hydraulic properties," Journal of Hydrology, vol. 238, no. 1-2, pp. 78-89, 2000.

[22] CMG, IMEX User's Guide, Computer Modeling Group, 2011.

[23] D. I. Potapenko, S. K. Tinkham, B. Lecerf et al., "Barnett Shale refracture stimulations using a novel diversion technique," in Proceedings of the SPE Hydraulic Fracture Technology Conference, SPE-119636, The Woodlands, Tex, USA, 2009.

[24] W. Yu and K. Sepehrnoori, "Simulation of gas desorption and geomechanics effects for unconventional gas reservoirs," in Proceedings of the SPE Western Regional Meeting, SPE-165377, Monterey, Calif, USA, April 2013. 

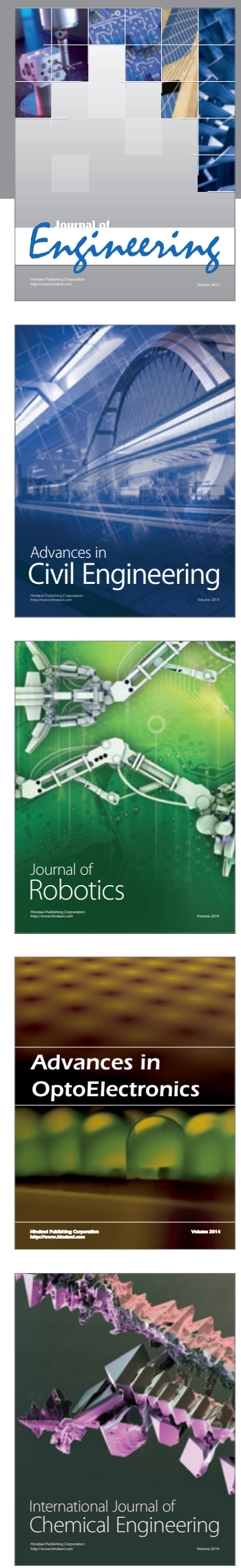

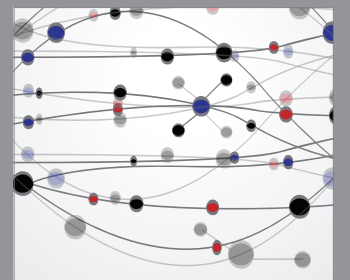

The Scientific World Journal
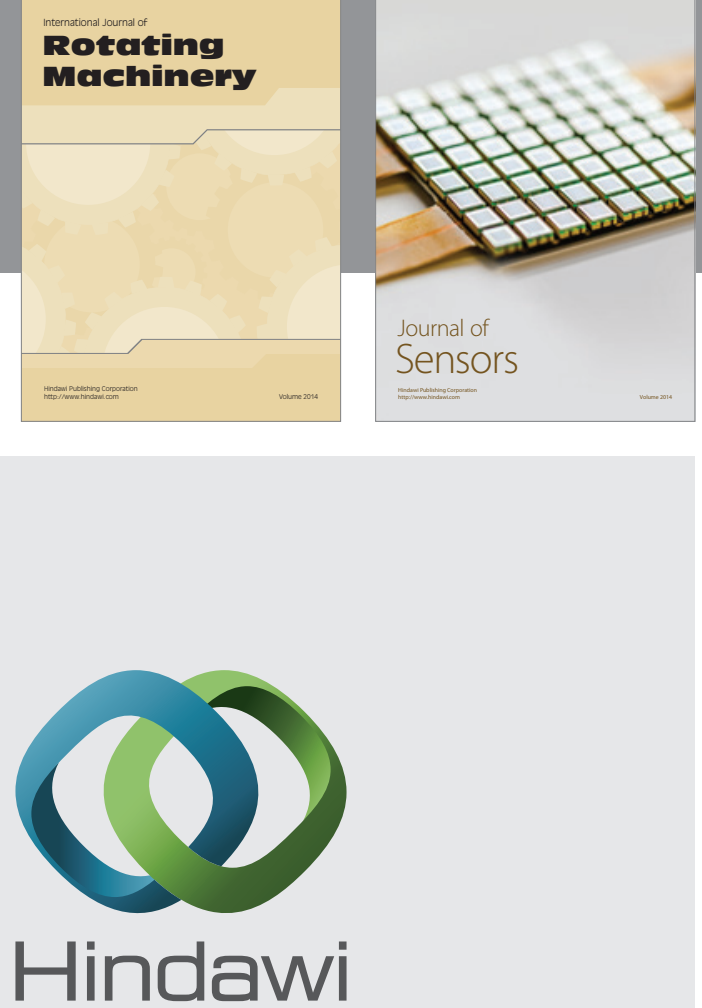

Submit your manuscripts at http://www.hindawi.com
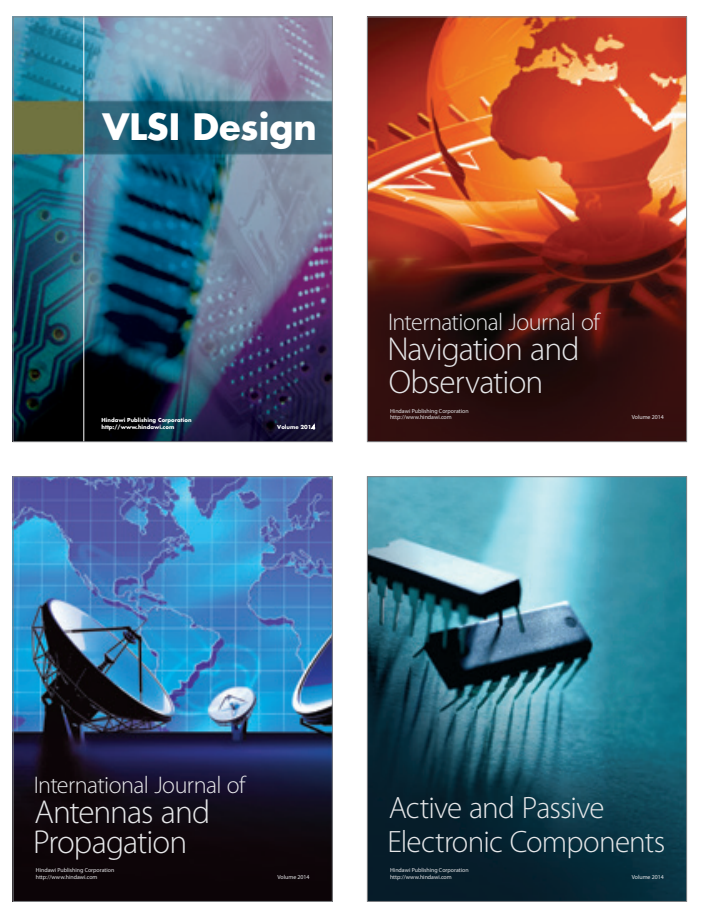
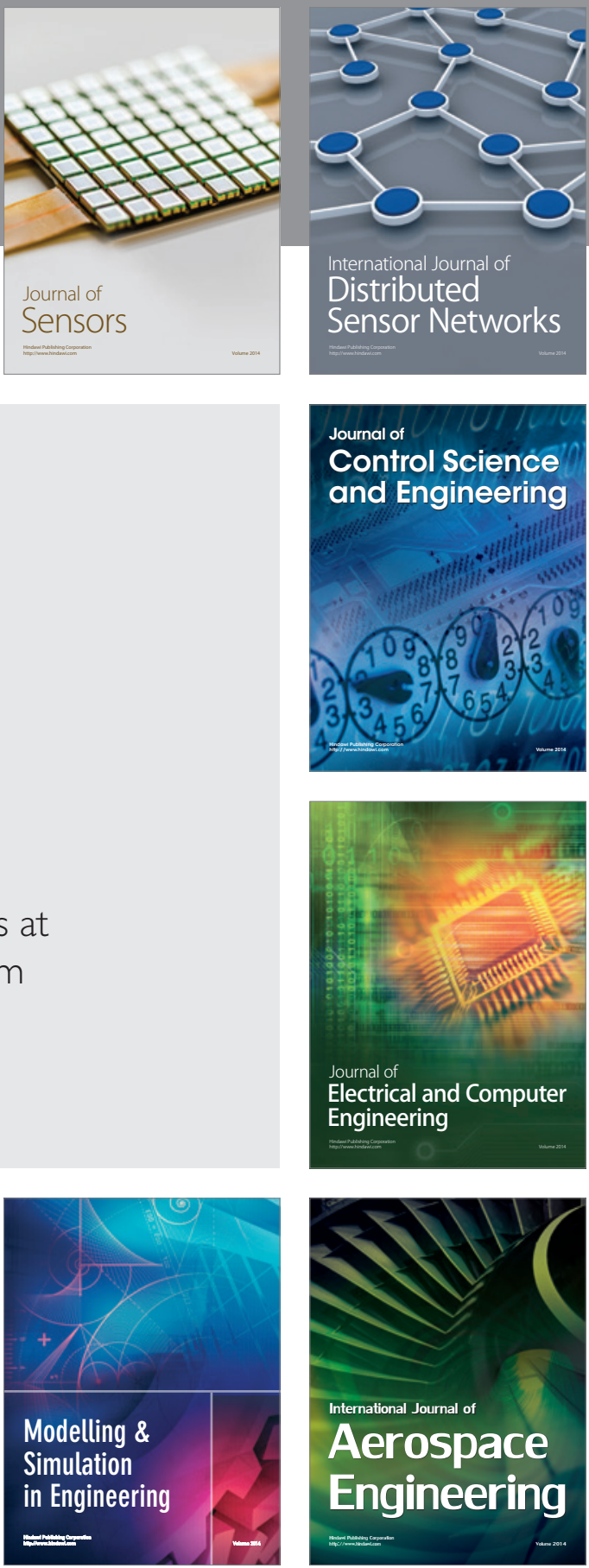

Journal of

Control Science

and Engineering
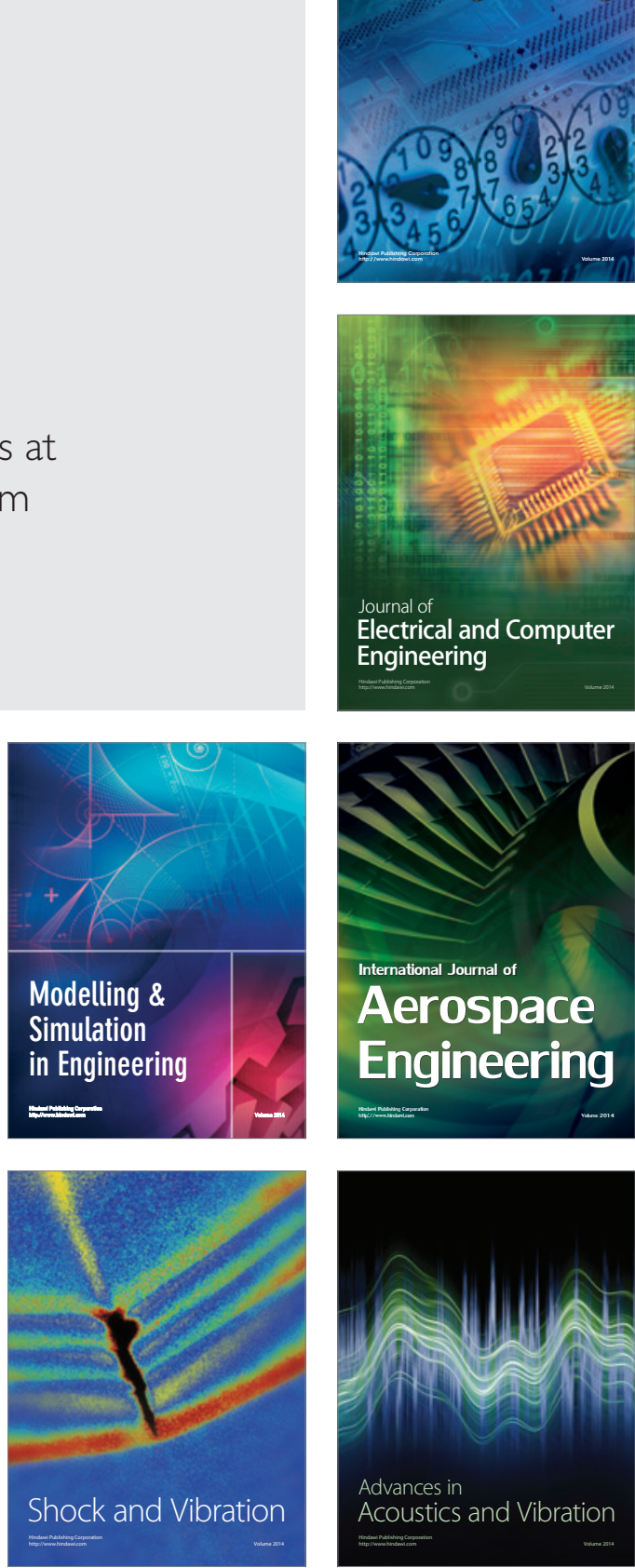